\author{
Michael A. Kuiper \\ Denise P. Veelo \\ Peter E. Spronk \\ Marcus J. Schultz
}

\section{Legislation on research involving patients who are (temporarily) unable to give informed consent: differences between European countries}

\author{
Accepted: 12 July 2007 \\ Published online: 8 August 2007 \\ (C) Springer-Verlag 2007
}

Sir: Recently Ciroldi et al. reported on the ability of family members to predict patient's consent to critical care research [1]. They showed that family members designated to serve as surrogate decision makers fail to accurately consent to research in one-third to one-half of cases.

We would like to recall a previous report on the same topic. In 2005 we asked representatives of 714 patients to grade their competence in giving surrogate informed consent for the temporarily incapable patient, from 1 ("very incompetent") to 10 ("very competent") [2]. This was done for two hypothetical situations: (a) in the case that a medical decision had to be made (i.e., the performance of a surgical procedure) and (b) in the event that the patient was considered to be a potential candidate to participate in critical care research (i.e., participation in a randomized controlled trial comparing a new therapy with standard care). If patients regained competence before discharge from the intensive care unit (ICU), they were asked to grade their representative for the task of giving informed consent in the same way. The most important finding of this study was that patients felt their surrogate de- cision makers were very capable of representing them in respect of medical decisions as well as participation in research [patients graded their surrogate decision makers 8.0 (interquartile range 7.0-9.0) for both decisions]; there was no significant difference in rating of the patients for the different representatives (spouses, parents, children, siblings, and others). We also found that representatives felt very confident in their ability to represent the patients [they graded themselves 8.0 (7.0-9.0)]; while there was a significant difference in confidence for the task of representing the patient in participation in research between spouses and parents at 8.0 (7.0-9.0), children at 7.5 (6.0-9.0), siblings at 7.0 (5.5-7.0), and others at $6.0(5.5-7.5)$ $(p=0.02)$, confidence level concerning medical decisions were similar for the different representatives.

The differences between the two studies are remarkable. One vital dissimilarity between our study and the one by Ciroldi et al. was timing of consent. Indeed, while Ciroldi et al. obtained their data at the time of discharge from the ICU, we acquired data early after admission to the ICU. It remains uncertain, however, whether this really explains the differences between the two studies. Ciroldi et al. hypothesize that patients and surrogates may be less inclined to give consent in a hypothetical situation than in real life. Although this may be the case for France, our data at least suggest this not to be the case for the Netherlands. Another difference between France and the Netherlands appears to speak against the suggestion that formal designation of surrogates improves the representation of patient's wishes: in contrast to France, where $10 \%$ of representatives are formal designated surrogates, in the Netherlands only $0.5 \%$ of the patients in our study had a legal representative.
The different results from these two studies underline the importance of studying this topic in a broader context: differences between countries should be recognized when changing legislation.

\section{References}

1. Ciroldi M, Cariou A, Adrie C, Annane D, Castelain V, Cohen Y, Delahaye A, Joly LM, Galliot R, Garrouste-Orgeas M, Papazian L, Michel F, Barnes NK, Schlemmer B, Pochard F, Azoulay E (2007) Ability of family members to predict patient's consent to critical care research. Intensive Care Med 33:807-813

2. Veelo DP, Spronk PE, Kuiper MA, Korevaar JC, van der Voort PH, Schultz MJ (2006) A change in the Dutch Directive on Medical Research Involving Human Subjects strongly increases the number of eligible intensive care patients: an observational study. Intensive Care Med 32:1845-1850

M. A. Kuiper - D. P. Veelo · P. E. Spronk · M. J. Schultz

Academic Medical Center, University of Amsterdam, Department of Intensive Care Medicine,

Amsterdam, Netherlands

D. P. Veelo · M. J. Schultz

Academic Medical Center, University of Amsterdam, Department of Anesthesiology, Amsterdam, Netherlands

D. P. Veelo · M. J. Schultz

Academic Medical Center, University of Amsterdam, Laboratory of Experimental Intensive Care and Anesthesiology,

Amsterdam, Netherlands

M. A. Kuiper · P. E. Spronk · M. J. Schultz Hermes Critical Care Group,

Amsterdam, Netherlands

M. A. Kuiper ( $)$

Medical Center Leeuwarden, Department of Intensive Care Medicine,

PO Box 888, 8901 BR Leeuwarden,

Netherlands

e-mail: mi.kuiper@wxs.nl;

m.kuiper@znb.nl

Tel.: +31-58-2866737

P. E. Spronk

Gelre Hospitals (location Lucas),

Department of Intensive Care Medicine,

Apeldoorn, Netherlands 